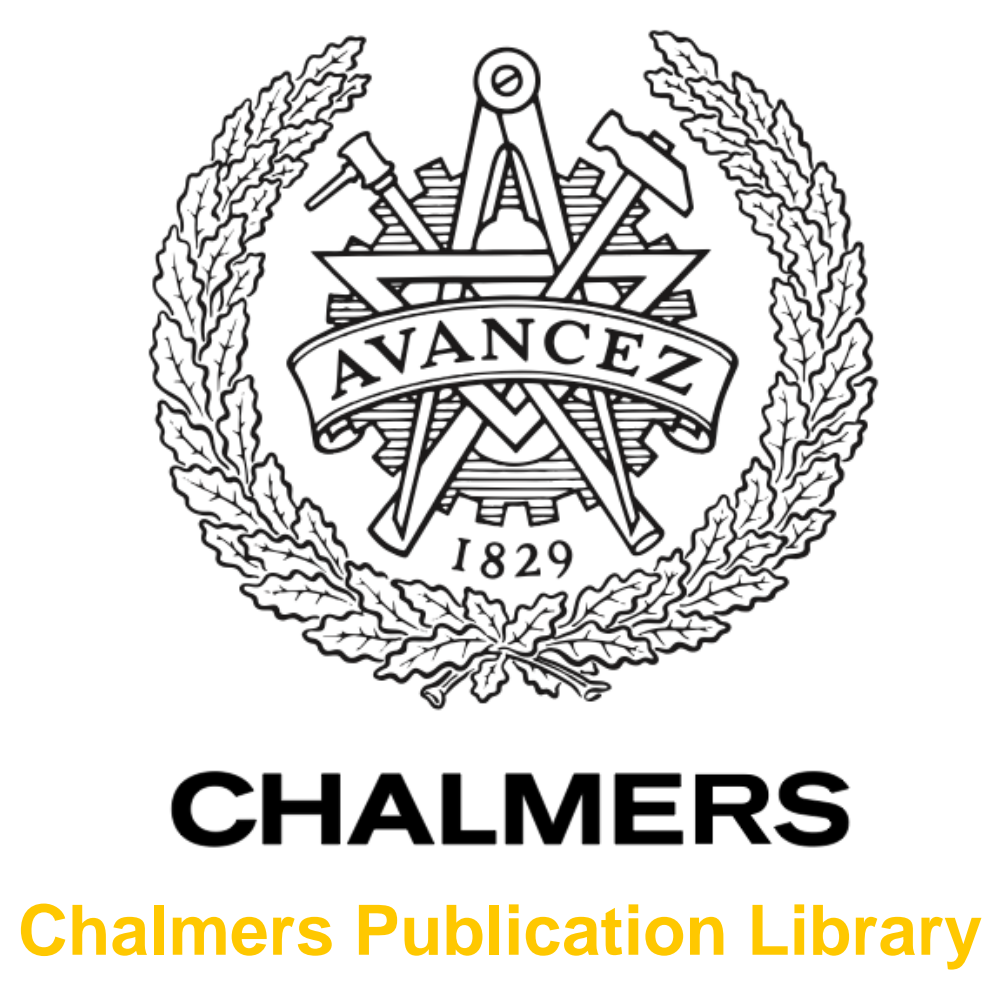

Metal-Free Graphene as Transparent Electrode for GaN-Based Light-Emitters

This document has been downloaded from Chalmers Publication Library (CPL). It is the author's version of a work that was accepted for publication in:

Japanese Journal of Applied Physics (ISSN: 0021-4922)

Citation for the published paper:

Stattin, M. ; Lockhart de la Rosa, C. ; Sun, J. (2013) "Metal-Free Graphene as Transparent Electrode for GaN-Based Light-Emitters". Japanese Journal of Applied Physics, vol. 52 pp. 08JG05.

http://dx.doi.org/10.7567/JJAP.52.08JG05

Downloaded from: http://publications.lib.chalmers.se/publication/177085

Notice: Changes introduced as a result of publishing processes such as copy-editing and formatting may not be reflected in this document. For a definitive version of this work, please refer to the published source. Please note that access to the published version might require a subscription.

Chalmers Publication Library (CPL) offers the possibility of retrieving research publications produced at Chalmers University of Technology. It covers all types of publications: articles, dissertations, licentiate theses, masters theses, conference papers, reports etc. Since 2006 it is the official tool for Chalmers official publication statistics. To ensure that Chalmers research results are disseminated as widely as possible, an Open Access Policy has been adopted.

The CPL service is administrated and maintained by Chalmers Library. 


\title{
Metal-Free Graphene as Transparent Electrode for GaN-Based Light-Emitters
}

\author{
Martin Stattin* , Cesar Lockhart de la Rosa, Jie Sun, August Yurgens, and Åsa Haglund \\ Department of Microtechnology and Nanoscience - MC2, Chalmers University of Technology, \\ 41296 Gothenburg, Sweden
}

\begin{abstract}
Graphene contacts to $\mathrm{p}-\mathrm{GaN}$ are considered as an alternative to indium-tin-oxide transparent electrodes in GaN based verticalcavity surface-emitting lasers (VCSELs). Contact properties were investigated on light-emitting diode and p-GaN test structures, where dielectric apertures were used to eliminate the influence of the metal pads used to bias the contacts. Using single layer graphene we were able to operate light emitting diodes with current densities of $300 \mathrm{~A} / \mathrm{cm}^{2}$. Addition of a second layer of graphene increased the maximum bias current to $1 \mathrm{kA} / \mathrm{cm}^{2}$. However, the contacts are non-linear and cannot withstand high current densities for a long time. The results are promising but further investigation and improvement is needed for graphene to be a viable alternative to indium-tin-oxide for blue VCSELs.
\end{abstract}

\section{Introduction}

In GaN-based vertical-cavity surface-emitting lasers (VCSELs) there is a need for a transparent current spreading layer. So far, indium-tin-oxide (ITO) has been the material of choice for the transparent electrode. ${ }^{1-5)}$ However, graphene has been suggested as an alternative to ITO providing lower optical absorption in the ultraviolet-blue regime for a similar sheet resistance, ${ }^{6)}$ and potential cost reductions. ${ }^{7)}$ The work functions of ITO and graphene are similar, but the Fermi level of graphene could be affected by charge carrier transport due to the low density of states in graphene and result in a lowered barrier between graphene and metals. ${ }^{8)}$ Recent experimental results support these findings for graphene on $\mathrm{p}-\mathrm{GaN}{ }^{9}{ }^{9}$ Thus utilizing graphene instead of ITO could possibly reduce the contact resistivity to $\mathrm{p}-\mathrm{GaN}$, which is a major concern in GaN-based VCSELs.

Graphene as a transparent conductive layer has in the literature been explored primarily for use in light emitting diodes (LEDs). ${ }^{10-13)}$ The main focus of the research has been on proof-of-concept. A few reports ${ }^{14,15)}$ indicate specific contact resistivity of $1-5 \Omega \mathrm{cm}^{2}$ between graphene and $\mathrm{p}-\mathrm{GaN}$, which is too large for device applications. Furthermore, in most of these investigations the test structure consists of pads with $\mathrm{p}-\mathrm{GaN} / \mathrm{graphene} / \mathrm{metal}$ contact. In graphene-LEDs most of the contact area is the graphene/p-GaN contact, without any metal. Also in VCSELs metals should be avoided due to the high absorption loss in them; it is thus important to investigate the graphene/p-GaN contacts without metals.

In this work, we have designed and fabricated test structures dedicated to the investigation of the pure, metal-free, graphene/p-GaN contact on $\mathrm{p}-\mathrm{GaN}$ samples as well as full light-emitting diode (LED) structures with current confining apertures similar to those used in GaN-based VCSELs.

\section{Experimental Procedure}

The epitaxial structures used for evaluating the graphene / $\mathrm{p}-\mathrm{GaN}$ contacts were a $\mathrm{p}-\mathrm{GaN}$ structure consisting of (15 $\mathrm{nm}$ pp-GaN) / (750 nm p-GaN) / $(2 \mu \mathrm{m}$ nid-GaN) and a LED structure consisting of (50 nm pp-GaN) / (150 nm p-GaN) / (20 nm p-AlGaN) / (92 nm nid-GaN with five $4 \mathrm{~nm}$ wide In$\mathrm{GaN}$ quantum wells with $12 \mathrm{~nm}$ barriers $) /(1.5 \mu \mathrm{m} \mathrm{n}-\mathrm{GaN})$ / (3 $\mu \mathrm{m}$ nid-GaN), both grown by metal-organic chemical vapour deposition (MOCVD) on sapphire substrate.

*E-mail: martin.stattin@ chalmers.se
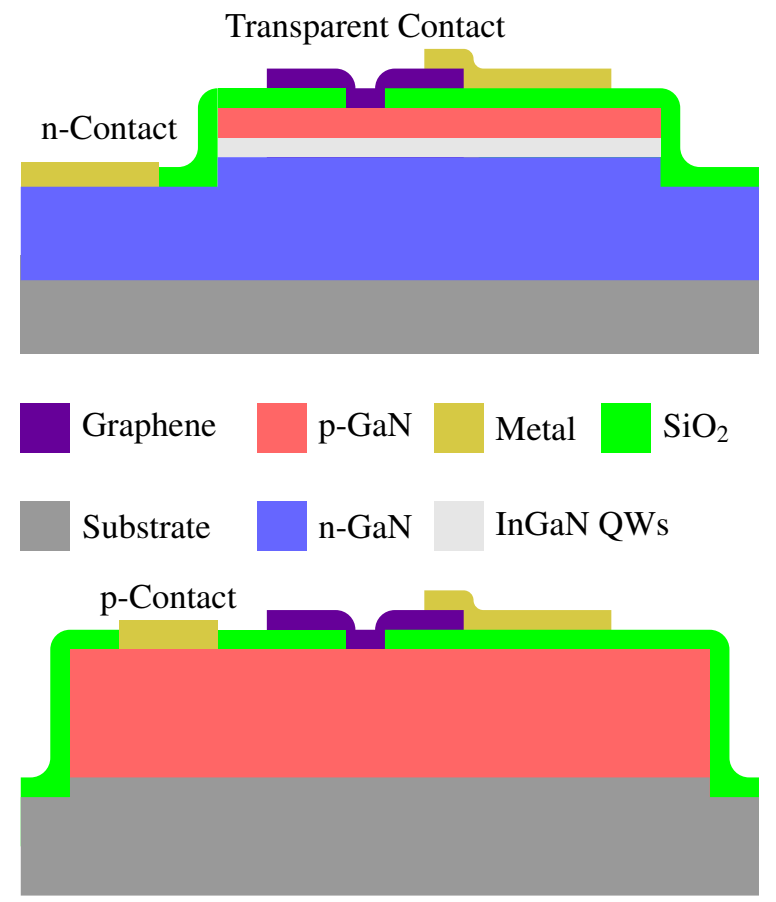

Fig. 1. (Color online) $\mathrm{The}^{\mathrm{SiO}_{2}}$ dielectric insulates the metal bondpad and ensures that the only current path is through the graphene/p-GaN interface. Test structures were fabricated on both LED (above) and p-GaN (below) samples.

A schematic view of the $\mathrm{p}-\mathrm{GaN}$ and LED test structures is shown in Fig. 1. The fabrication started with etching mesas using $\mathrm{Cl}_{2} / \mathrm{Ar}$ reactive ion etching into the nid-GaN and nGaN layers, respectively. The samples were cleaned in BASF Sioetch MT 06/01, buffered oxide etch (BOE), for 5 min before a $50 \mathrm{~nm}$ thick $\mathrm{SiO}_{2}$ layer was sputtered on top. Openings for metal contacts (aperture diameter of 2, 4, 6, 8, 10, and $12 \mu \mathrm{m}$ ) in the $\mathrm{SiO}_{2}$ were etched for $30 \mathrm{~s}$ in BOE. Pd/Au $(30 / 200 \mathrm{~nm})$ and $\mathrm{Ti} / \mathrm{Al} / \mathrm{Ti} / \mathrm{Au}(5 / 10 / 15 / 200 \mathrm{~nm})$ contacts were deposited by evaporation, on the $\mathrm{p}-\mathrm{GaN}$ and LED structures, respectively. Rapid thermal annealing in $\mathrm{N}_{2}$ atmosphere was then done for 1 minute at $800^{\circ} \mathrm{C}$ for the n-contacts on LED samples and for 15 minutes at $550^{\circ} \mathrm{C}$ for the p-contacts on $\mathrm{p}$ $\mathrm{GaN}$. Holes in the $\mathrm{SiO}_{2}$ for the graphene contacts were opened by etching in BOE for $30 \mathrm{~s}$. The graphene was grown on $\mathrm{Cu}$ substrates by chemical vapour deposition (CVD); for growth details see 16. The growth gives large uniform single layer 


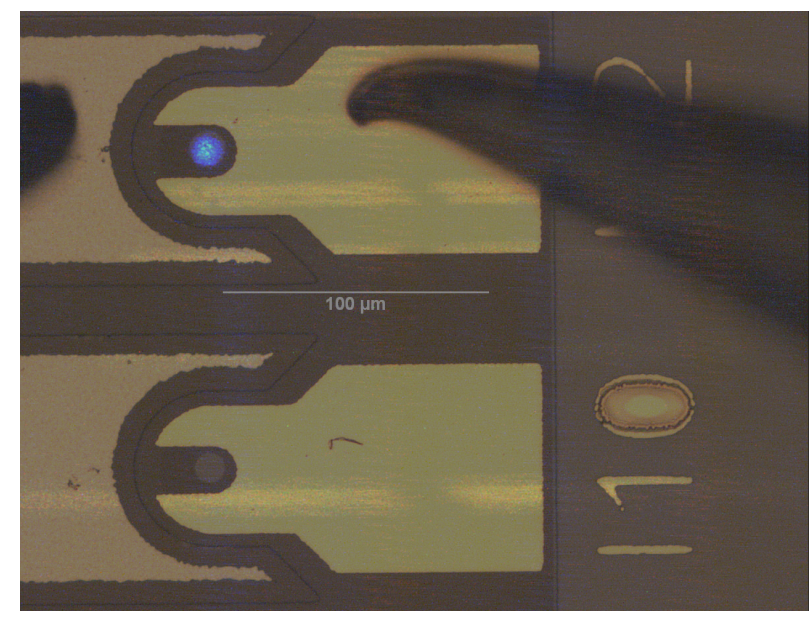

Fig. 2. (Color online) Spontaneous emission from LED with $12 \mu \mathrm{m}$ diameter aperture graphene contact during I-V-scan.

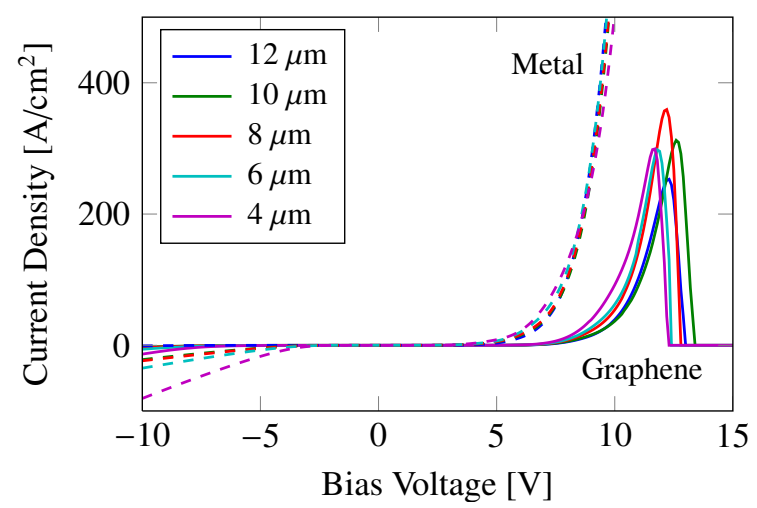

Fig. 3. (Color online) Comparison of current density for metal (dashed) and graphene (solid) contacts to LEDs with different aperture diameters.

graphene, verified by Raman spectra. The graphene is liftedoff from the $\mathrm{Cu}$ substrate by electrolytic delamination, ${ }^{17,18)}$ and is then transferred to the $\mathrm{p}-\mathrm{GaN}$. The transfer process was repeated to achieve not only single but also dual layer graphene. The graphene was then patterned using $\mathrm{O}_{2}$ plasma and bond pads of $\mathrm{Ti} / \mathrm{Pd} / \mathrm{Au}(5 / 30 / 200 \mathrm{~nm})$ were electron-beam evaporated. On the LED chips, reference components were also fabricated with $\mathrm{Ti} / \mathrm{Pd} / \mathrm{Au}$ contacts instead of graphene.

The graphene/p-GaN contacts were evaluated using the Keithley 4200-SCS parameter analyzer. The maximum applied voltage during current-voltage (I-V)-scans was gradually increased to examine both repeatability and breakdown conditions. Contact stability over time was evaluated by applying a fixed voltage and monitoring the current.

\section{Results and Discussion}

The imaged spontaneous emission from a $12 \mu \mathrm{m}$ diameter LED is shown in Fig. 2. It confirms current confinement by the aperture and current injection through the graphene to the top $\mathrm{p}-\mathrm{GaN}$ layer of the LED.

The I-V characteristics for LEDs are shown in Fig. 3. The turn-on voltage for the LEDs with graphene contacts is about $3 \mathrm{~V}$ higher than for the LEDs with $\mathrm{Ti} / \mathrm{Pd} / \mathrm{Au}$ contacts. The $\mathrm{Ti} / \mathrm{Pd} / \mathrm{Au}$ contacts are not conventional contacts to $\mathrm{p}-\mathrm{GaN}$, and give a slightly larger turn-on voltage compared to ohmic contacts. The metal contacts to $\mathrm{n}-\mathrm{GaN}$ were ohmic. The LEDs

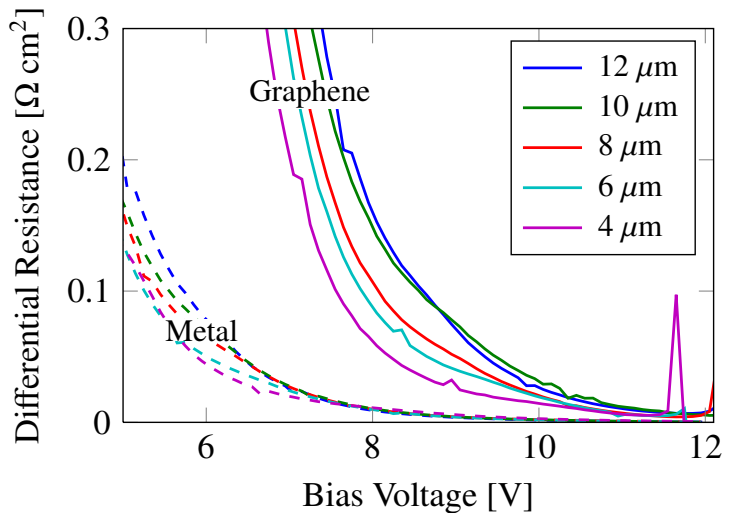

Fig. 4. (Color online) Comparison of differential specific resistance for metal (dashed) and graphene (solid) contacts to LEDs with different aperture diameters.

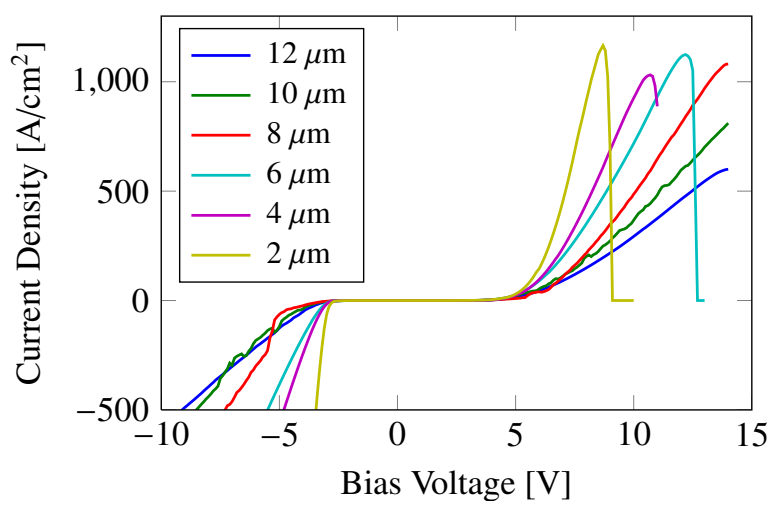

Fig. 5. (Color online) Current density as a function of voltage for dual layer graphene on $\mathrm{p}-\mathrm{GaN}$, for contacts with different aperture diameters.

with graphene contacts break-down after a current density of around $300 \mathrm{~A} / \mathrm{cm}^{2}$ has been reached, independent of aperture diameter, and the damage is irreversible. After turn-on voltage has been reached the differential resistance of the LEDs with graphene contacts is less than $0.1 \Omega \mathrm{cm}^{2}$, i.e., approaching that of the LEDs with metal contacts, Fig. 4.

Single and dual layer graphene contacts were fabricated on p-GaN samples. The single layer graphene has a sheet resistance of $1000 \Omega / \square$ and the dual layer graphene has 500 $\Omega / \square$. Figure 5 show I-V-characteristics of dual layer contacts. The I-V-curves are not symmetric, and show a forward voltage barrier that is larger than the reverse voltage barrier. As seen in the figure, the slopes of the I-V-curves are different, which is due to the differential resistance being dominated by the lateral resistance in the $\mathrm{p}-\mathrm{GaN}$ layer. This effect was also observed in the I-V-characteristics for the LEDs, but less pronounced due to the larger conductivity of the n-GaN layer. The dual layer graphene contacts were able to withstand current densities of around $1 \mathrm{kA} / \mathrm{cm}^{2}, 2-3$ times more than that of single layer graphene contacts. $1 \mathrm{kA} / \mathrm{cm}^{2}$ is close to the threshold requirements of $3 \mathrm{kA} / \mathrm{cm}^{2}$ for $\mathrm{GaN}$-based VCSELs. ${ }^{1)}$

The stability of the graphene contacts at low forward bias is shown in Fig. 6. The contacts are degraded after a few minutes of operation, and the degradation is likely caused by the thermal oxidation of the graphene layer. Similar degradation effects have been observed by other groups. ${ }^{12)}$ 


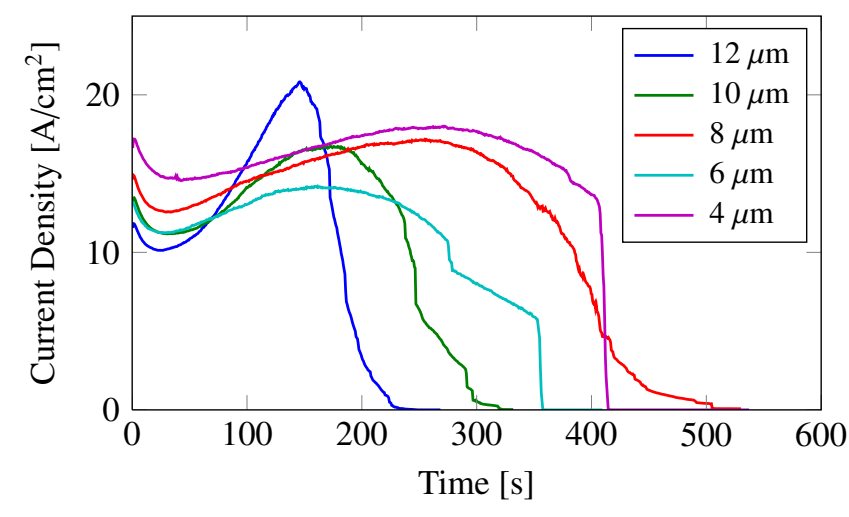

Fig. 6. (Color online) Current density as a function of time with a forward bias of $5 \mathrm{~V}$ on for dual layer graphene on $\mathrm{p}-\mathrm{GaN}$ showing degradation of the dual layer graphene contacts with different aperture diameters.

The graphene contacts may have been negatively affected by plasma damage and oxidation of the thin pp-GaN contacting layer during sputtering of $\mathrm{SiO}_{2}$. Circular transmission line measurements show that the $\mathrm{Pd} / \mathrm{Au}$ contacts on $\mathrm{p}-\mathrm{GaN}$ were slightly nonlinear and have three times larger contact resistivity than samples where $\mathrm{Pd} / \mathrm{Au}$ contacts were applied without $\mathrm{SiO}_{2}$ deposition and removal.

\section{Conclusions}

We have demonstrated the use of graphene as a transparent electrode on GaN-based LEDs without metal near the transparent contact. A dual layer graphene was able to withstand current densities of $1 \mathrm{kA} / \mathrm{cm}^{2}$, which is close to the required threshold current density in blue GaN-based VCSELs. However, the graphene/p-GaN contacts are not ohmic and degrade irreversibly under forward bias, also at low current densities. For graphene to be viable as a transparent contact for GaN based VCSELs, the contact stability must be improved. Efforts towards reducing the contact resistivity are needed, where direct growth of graphene ${ }^{19)}$ on $\mathrm{p}-\mathrm{GaN}$ could be an interesting option to explore. The use of coating layers blocking oxygen from reaching the contact interface could also potentially improve stability.

\section{Acknowledgments}

The epitaxial structures were provided by Professor Grandjean's group at École Polytechnique Federale de Lausanne,
Switzerland. The project was funded by Knut and Alice Wallenberg Foundation (KAW) and the Swedish Research Council (VR).

1) D. Kasahara, D. Morita, T. Kosugi, K. Nakagawa, J. Kawamata, Y. Higuchi, H. Matsumura, and T. Mukai: Appl. Phys. Express 4 (2011) 072103.

2) S.-C. Wang, T.-C. Lu, H.-C. Kuo: Proc. of SPIE 8276 (2012) 827607.

3) T. Onishi, O. Imafuji, K. Nagamatsu, M. Kawaguchi, K. Yamanaka, and S. Takigawa: IEEE J. Quantum Electron. 48 (2012) 1107.

4) C. Holder, J. S. Speck, S. P. DenBaars, S. Nakamura, and D. Feezell: Appl. Phys. Express 5 (2012) 092104.

5) G. Cosendey, A. Castiglia, G. Rossbach, J.-F. Carlin, and N. Grandjean: Appl. Phys. Lett. 101 (2012) 151113.

6) F. Bonaccorso, Z. Sun, T. Hasan, and A. C. Ferrari: Nat. Photonics 4 (2010) 611.

7) S. Bae, H. Kim, Y. Lee, X. Xu, J.-S. Park, Y. Zheng, J. Balakrishnan, T. Lei, H. R. Kim, Y. I. Song, Y.-J. Kim, K. S. Kim, B. Ozyilmaz, J.-H. Ahn, B. H. Hong, and S. Iijima: Nat. Nanotechnol. 5 (2010) 574.

8) G. Giovannetti, P. A. Khomyakov, G. Brocks, V. M. Karpan, J. van den Brink, and P. J. Kelly: Phys. Rev. Lett. 101 (2008) 026803.

9) H. Zhong, Z. Liu, G. Xu, Y. Fan, J. Wang, X. Zhang, L. Liu, K. Xu, and H. Yang: Appl. Phys. Lett. 100 (2012) 122108.

10) Y. Zhang, L. Wang, X. Li, X. Yi, N. Zhang, J. Li, H. Zhu, and G. Wang: J. Appl. Phys. 111 (2012) 114501.

11) S. Chandramohan, J. H. Kang, Y. S. Katharria, N. Han, Y. S. Beak, K. B. Ko, J. B. Park, H. K. Kim, E.-K. Suh, and C.-H. Hong: Appl. Phys. Lett. 100 (2012) 023502.

12) B.-J. Kim, C. Lee, Y. Jung, K. H. Baik, M. A. Mastro, J. K. Hite, J. Charles, R. Eddy, and J. Kim: Appl. Phys. Lett. 99 (2011) 143101.

13) T. H. Seo, T. S. Oh, S. J. Chae, A. H. Park, K. J. Lee, Y. H. Lee, and E.-K. Suh: Jpn. J. Appl. Phys 50 (2011) 125103.

14) S. Chandramohan, J. H. Kang, Y. S. Katharria, N. Han, Y. S. Beak, K. B. Ko, J. B. Park, B. D. Ryu, H. K. Kim, E.-K. Suh, and C.-H. Hong: J. Phys. D 45 (2012) 145101.

15) J. M. Lee, H. Y. Jeong, K. J. Choi, and W. I. Park: Appl. Phys. Lett. 99(2011) 041115.

16) J. Sun, N. Lindvall, M. Cole, K. Angel, T. Wang, K. Teo, D. Chua, J. Liu, and A. Yurgens: IEEE Trans. Nanotechnol. 11 (2012) 255.

17) L. Gao, W. Ren, H. Xu, L. Jin, Z. Wang, T. Ma, L.-P. Ma, Z. Zhang, Q. Fu, L.-M. Peng, X. Bao, and H.-M. Cheng: Nat. Commun. 3 (2012) 699.

18) C. J. Lockhart de la Rosa, J. Sun, N. Lindvall, M. T. Cole, Y. Nam, M. Löffler, E. Olsson, K. B. K. Teo, and A. Yurgens: to be pulished in Appl. Phys. Lett.

19) G. Ding, Y. Zhu, S. Wang, Q. Gong, L. Sun, T. Wu, $\mathrm{X}$. Xie, and $\mathrm{M}$. Jiang: to be published in Carbon [DOI: 10.1016/j.carbon.2012.11.018]. 